\title{
Corrosion resistance of ZrTi alloys with hydroxyapatite-zirconia-silver layer in simulated physiological solution containing proteins for biomaterial applications
}

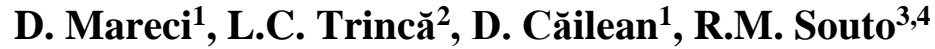 \\ ${ }^{1}$ Technical University “Gheorghe Asachi” of Iasi, Faculty of Chemical Engineering and Environmental \\ Protection, D. Mangeron, Iasi, 700050, Romania \\ 2 "Ion Ionescu de la Brad" University of Agricultural Science and Veterinary Medicine, Faculty of \\ Horticulture, Science Department, 3, Mihail Sadoveanu Alley, Iaşi, 700490, Romania \\ ${ }^{3}$ Department of Physical Chemistry, Universidad de La Laguna, E-38200 La Laguna (Tenerife, Canary \\ Islands), Spain \\ ${ }^{4}$ Institute of Material Science and Nanotechnology, Universidad de La Laguna, E-38200 La Laguna \\ (Tenerife, Canary Islands), Spain.
}

\begin{abstract}
The degradation characteristics of hydroxyapatite-zirconia-silver films (HA-ZrO2-Ag) coatings on three ZrTi alloys were investigated in Ringer's solution containing 10\% human albumin protein at 37 ${ }^{\circ} \mathrm{C}$. Samples were immersed for 7 days while monitored by electrochemical impedance spectroscopy (EIS) and linear potentiodynamic polarization (LPP). The electrochemical analysis in combination with surface analytical characterization by scanning electron microscopy (SEM/EDX) reveals the stability and corrosion resistance of the $\mathrm{HA}-\mathrm{ZrO}_{2}-\mathrm{Ag}$ coated $\mathrm{ZrTi}$ alloys. The characteristic feature that describes the electrochemical behaviour of the coated alloys is the coexistence of large areas of the coating presenting pores in which the ZrTi alloy substrate is exposed to the simulated physiological environment. The EIS interpretation of results was thus performed using a two-layer model of the surface film. The blocking effect in the presence the human albumin protein produces an enhancement of the corrosion resistance. The results disclose that the Zr45Ti alloy is a promising material for biomedical devices, since electrochemical stability is directly associated to biocompatibility.
\end{abstract}

Keywords: ZrTi alloys; $\mathrm{HA}-\mathrm{ZrO}_{2}-\mathrm{Ag}$ nanoparticles; pulsed laser deposition; EIS; SEM. 


\section{Introduction}

Titanium and its alloys are widely used in biomedical applications due to their characteristic low density, and high mechanical and corrosion resistances [1-3]. In fact, corrosion, and the subsequent ion release into the physiological environment, is an important characteristic affecting the biocompatibility of implant alloys [4]. Despite the outstanding passivity of titanium and its alloys conferred by the compact and stable oxide films spontaneously formed on their surface [5,6], the observation of localized electrochemical activity in saline environments [7-9] may account for reports of ion release and metallosis in vivo [10-13]. As result, there is growing concern on the long-range effects of hazardous metal ions such as $\mathrm{Al}$ and $\mathrm{V}[14,15]$, which are often present in titanium-based orthopedic implants. This concern has promoted the search for alternative alloys suitable for bone replacement and fixation as well as for dentistry with greater corrosion resistance while exhibiting high biocompatibility characteristics [3]. Among them, binary Zr-Ti alloys have shown good mechanical characteristics [16] while high corrosion resistance was conferred by the combined effect of $\mathrm{TiO}_{2}$ and $\mathrm{ZrO}_{2}$ jointly forming the protective passive layers [17-20]. Even higher corrosion resistance of the passive films was achieved by prior thermal oxidation of the cast materials in air [20,21].

Enhanced osseointegration of titanium-based implant materials is achieved by coating them with a thin layer of hydroxyapatite $\left(\mathrm{HA}, \mathrm{Ca} 10\left(\mathrm{PO}_{4}\right)_{6}(\mathrm{OH})_{2}\right)$ [22]. This coating must be porous in order to assure good osteointegration [23], but it may affect the corrosion behavior of the substrate. HA has a similar mineral constitution to bone, and thus shows bioactive properties favoring tissue response that enhances fixation to hard bone [24]. Though several techniques can be employed to apply HA layers on metal substrates (namely i plasma spray [25,26], electron beam evaporation, radio frequency sputtering [27], electrophoretic deposition [27,28], sol-gel deposition [29], and pulsed laser deposition [30]), some of these methods present drawbacks. In plasma spraying, the particles are melted at high temperature and produce crystalline areas within an amorphous calcium phosphate matrix. An amorphous and phosphorous deficient material is obtained by radio frequency sputtering, whereas ion beam sputtering

cannot coat odd shaped objects. Electrophoretic techniques produce layers with poor adhesion characteritics.

Other coatings have been investigated for biocompatibility enhancement. Zirconia demonstrated superior characteristics for in vitro bioactivity, because this ceramic material possesses the ability to induce bone formation in biological environment [31-35]. Recent coating strategies also involve the use 
of antimicrobial and antibacterial agents in order to reduce the eventuality of infections resulting from surgical procedures [36,37], such as silver or silver ions [38-41]. It was found that TiAg alloys present a high corrosion resistance [42]. Alternately, antimicrobial activity by silver can be gained by using metal nanoparticles in coatings [43,44].

The aim of this paper is the improvement of the biocompatibility characteristics of ZrTi alloys by PLD coating with composite hydroxiapatite-zirconia layers containing silver nanoparticles as antimicrobial agent whereas no significantly deteriorating the corrosion resistance of the material. Pulsed laser deposition (PLD), also called laser ablation, is a reliable and inexpensive method for the obtention of thin films of simple or complex compounds. The PLD method involves the interaction of a laser beam with a target material [45]. Since the deposition chamber is a "clean" reactor, the transfer of the target to the substrate is stoichiometric, and the thickness of the film can be controlled by the number of pulses deposition process. The formed plasma plume rapidly condenses onto the substrate and grows a thin film [46]. The corrosion resistance of the coated ZrTi alloys was characterized using electrochemical techniques during their exposure to Ringer' solution modified with $10 \%$ human albumin protein, because implants materials inserted into a human body are usually surrounded by blood-rich tissue, and serum proteins in the blood are known to influence metal corrosion [47-54].

\section{Experimental}

\subsection{Materials and sample preparation}

Binary Zr-Ti alloys, of compositions Zr5Ti, Zr25Ti, and Zr45Ti, were fabricated by a multiple electron beam drip melting method as described elsewhere [20]. Cylindrical ingots of $40 \mathrm{~mm}$ diameter and about $100 \mathrm{~mm}$ length were obtained.

The composite $\mathrm{HA}-\mathrm{ZrO}_{2}$ coating containing Ag nanoparticles was deposited on the $\mathrm{Zr}$-Ti alloy samples as described next. The ultrasonic irradiation (US) method has been used to generate Ag nanoparticles [55-57]. In the first stage, a Sonopuls HD 3200 horn-type reactor (Bandelin, Berlin, Germany) was used to prepare the samples, where the following US conditions were maintained: $20 \mathrm{kHz}$ frequency and $81 \mu \mathrm{m}$ amplitude of the acoustic wave. The equipment also displays the amount of energy delivered to the sample by the ultrasonic waves. A schematic representation of the preparation stage is indicated in Figure 1. Firstly, $1 \mathrm{~L} 0.1 \mathrm{M} \mathrm{AgNO}_{3}$ solution was irradiated for 20 minutes with a total amount of energy dissipated in this sample of 170,043 kJ. The second solution treated under the same 
ultrasonic conditions was a $21.1 \mathrm{~g} \mathrm{~L}^{-1} \mathrm{CaCl}_{2}$ (volume $200 \mathrm{~mL}$ ) for $5 \mathrm{~min}$ and 38,910 $\mathrm{kJ}$ dissipated in the

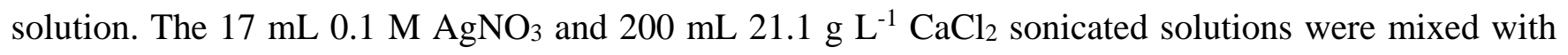
$200 \mathrm{~mL}$ solution $38.8 \mathrm{~g} \mathrm{~L}^{-1} \mathrm{Na}_{3} \mathrm{PO}_{4} \cdot 12 \mathrm{H}_{2} \mathrm{O}$ and irradiated for another 5 minutes. In the 3-components mixture (Mix 1, Figure 1), 4.09 g $\mathrm{ZrO}_{2}$ was added and ultrasonic irradiation continued for another 5 minutes. The mean diameter of the particles and size distribution were analyzed by laser light diffraction with a Shimadzu SALD-7001 (Kyoto, Japan).

For PLD coating, the $\mathrm{HA}-\mathrm{ZrO}_{2}-\mathrm{Ag}$ solution was calcinated at $675{ }^{\circ} \mathrm{C}$ to get crystalline target surface. The depositions were done in a stainless steel vacuum chamber, equipped with a dry pump (Bluffton Motor Works, Bluffon, IN, USA) which ensured $10^{-2}$ torr pressure during film growth (details of the experimental set-up are given in [57]). The HA ( $\mathrm{Zr}$, Ag doped) target was placed on a micrometric precision 3D translation stage and moved constantly during deposition. The second harmonic of an NdYAG laser (Quantel Brilliant, Orléans, France) was focused on the bulk source material by a $35 \mathrm{~cm}$ focal point lens at a $45^{\circ}$ angle with respect to the target surface. The estimated impact area was $0.8 \mathrm{~mm}^{2}$ while the laser energy was set at $40 \mathrm{~mJ}$; this led to a fluence of $\sim 5 \mathrm{~J} \mathrm{~cm}^{-2}$. The ZrTi substrate alloys were placed at a distance of $3 \mathrm{~cm}$ from the $\mathrm{HA}-\mathrm{ZrO}_{2}-\mathrm{Ag}$ target surface. The deposition time was $30 \mathrm{~min}$.

The morphological analysis has been performed by scanning electron microscopy (SEM). A VEGA II LMH SEM (Tescan, Brno, Czech Republic) provided with energy dispersive X-ray spectroscopy (EDX) analysis (model XFlash, Bruker, Billerica, MA, USA) was employed. Compositional characterization of the as-prepared samples was performed using a TENSOR 27 microFourier transform infrared (FTIR) spectrometer (Bruker Optics, Brno, Czech Republic) coupled with HYPERION 1000 FTIR microscope (Bruker, Billerica, MA, USA). The FTIR spectra of the calcinated samples were registered with a Bomem MB-104 spectrophotometer (Quebec, Canada). The spectral resolution used was $4 \mathrm{~cm}^{-1}$. Fifty scans were added per sample spectrum, and Fourier transformation of the spectra was done using the Win Bomem Easy 3.5 software package.

\subsection{Electrochemical techniques}

The electrochemical tests were run in a glass corrosion flow cell kit (C145/170, Radiometer, Copenhagen, Denmark) containing $200 \mathrm{ml}$ of Ringer's solution with 10\% human albumin protein (Kedrion S.p.A. Barga, Italy). The temperature and $\mathrm{pH}$ were $37 \pm 1^{\circ} \mathrm{C}$ and 7.2 , respectively. The test specimens were placed in a glass corrosion cell, which was filled with freshly prepared electrolyte. A saturated calomel electrode (SCE) was used as the reference electrode and a platinum coil as the counter 
electrode. All potential values given in this article are referred to SCE. The measurement was managed by a PAR 4000 potentiostat controlled by a personal computer with dedicate software (PowerCorr, Princeton Applied Research, Princeton, NJ, USA).

EIS measurements were performed after the samples were immersed in electrolyte at open circuit potential, for different periods of time, namely 1 hour, 1 day, and 7 days. The alternating current (AC) impedance spectra were obtained with a scan frequency ranging from $100 \mathrm{kHz}$ to $10 \mathrm{mHz}$, using a potential amplitude of $10 \mathrm{mV}$. In order to supply quantitative support for discussions of the experimental EIS results, an appropriate model (ZSimpWin, Princeton Applied Research, Princeton, NJ, USA) for equivalent circuit (EC) quantification was employed. The usual guidelines for the selection of the bestfit EC were followed: a minimum number of circuit elements are employed and the $\chi^{2}$ error was suitably low $\left(\chi^{2}<10^{-4}\right)$, and the error associated with each element was up to 5\%. Instead of pure capacitors, constant phase elements (CPE) were introduced in the fitting procedure to obtain good agreement between simulated and experimental data [58].

Measurement of linear potentiodynamic polarization curves was initiated after 7 days exposure to the test environment. These tests were conducted by stepping the potential using a scanning rate of 1 $\mathrm{mV} \mathrm{s}^{-1}$ from -1.0 VsCE to +1.0 VsCE. The potentiodynamic polarization curves were plotted, and the corresponding values for the zero current potential $\left(E_{\mathrm{ZCP}}\right)$, and the corrosion current density $\left(j_{\text {corr }}\right)$, were determined. Electrochemical measurements were made in triplicate, and the analysis of variance (ANOVA) was performed using a Tukey post hoc test $(p<0.05)$.

\section{Results and discussion}

The average diameter of the $\mathrm{HA}-\mathrm{ZrO}_{2}-\mathrm{Ag}$ particles used to coat $\mathrm{ZrTi}$ alloys was $70 \mathrm{~nm}$, as deduced from the size distribution profile presented in Figure 2. After the coating was applied on the alloys, the formation of round nanoparticles on the surface of the $\mathrm{HA}-\mathrm{ZrO}_{2}-\mathrm{Ag}$ coated thin films is observed in the scanning electron micrographs of Figure 3. EDX analysis performed on the $\mathrm{HA}-\mathrm{ZrO}_{2}$ Ag coated $\mathrm{ZrTi}$ alloys delivered $\mathrm{Ca} / \mathrm{P}$ ratios $=1.66$ in the $\mathrm{HA}-\mathrm{ZrO}_{2}-\mathrm{Ag}$ coated thin films, a value close to the theoretical value 1.67 in HA. The occurrence of HA in the coating was further evidenced using Fourier transform infrared spectroscopy (FTIR). The basic bands characteristic for apatite compounds, reflecting the vibrations of the $\mathrm{PO}_{4}$ group (contained in apatite) in the range $960-1100 \mathrm{~cm}^{-1}$ and around 
$600 \mathrm{~cm}^{-1}$ are also found in the coated ZrTi materials as shown in Figure 4. For the sake of comparison, the $\mathrm{HA}-\mathrm{ZrO}_{2}-\mathrm{Ag}$ spectrum taken from OPUS software library was also included in the graph.

Electrochemical impedance spectroscopy (EIS) experiments were performed on the samples left at the open circuit potential spontaneously developed in the test environment. Typical impedance spectra of the $\mathrm{HA}-\mathrm{ZrO}_{2}-\mathrm{Ag}$ coated $\mathrm{ZrTi}$ alloys measured at different exposure times during their immersion in Ringer's solution containing albumin protein are shown in Figures 5-7. They are displayed in both complex impedance (Nyquist diagram) and amplitude/phase angle (Bode diagram) plots. Changes in the impedance characteristics as a result of the exposure of the $\mathrm{HA}-\mathrm{ZrO}_{2}-\mathrm{Ag}$ coated $\mathrm{ZrTi}$ alloys to the Ringer's solution could be performed by comparing the spectra. However, Bode plots are more indicated for the investigation of changes in the electrochemical characteristics of the system. It was observed that upon immersion of the various $\mathrm{HA}-\mathrm{ZrO}_{2}-\mathrm{Ag}$ coated $\mathrm{ZrTi}$ alloys in the test solution, variations in the impedance spectra occurred already during the first day. The impedance spectra exhibit two time constant at all exposure times. In the high frequency part the impedance characteristics result from the penetration of the test solution through a porous thin film, whereas the low frequency part accounts for the processes taking place at the substrate/test solution interface. Within the intermediate frequency part, the Bode diagrams show straight lines with slopes smaller than the value -1 and a phase angle smaller than $90^{\circ}$. These features are evidences of frequency dispersion and can be attributed to the occurrence of inhomogeneities of the solid surface. That is, the $\mathrm{HA}-\mathrm{ZrO}_{2}-\mathrm{Ag}$ thin film formed on the $\mathrm{ZrTi}$ alloys is porous. Low impedance modulus values in the order of $10^{4} \Omega \mathrm{cm}^{2}$ were measured even at the earliest exposures, whereas the general response of the system can be described as resistive over most of the frequency range (as characterized by phase angles smaller than 45 degrees).

For the interpretation of the electrochemical behavior of a system from EIS spectra, an appropriate physical model is required. An equivalent circuit (EC) provides the most relevant corrosion parameters applicable to the substrate/electrolyte system. Based on the inspection of the Bode-phase plots, the EC with two times constants shown in Figure 8 was adopted. The EC consists of the following elements: a solution resistance $\left(R_{\text {sol }}\right)$ of the test electrolyte, the constant phase element $\left(Q_{1}\right)$ of the intact coating layer, the charge transfer resistance associated with the penetration of the electrolyte trough the pores existing in the coating $\left(R_{1}\right)$, and the $\left(R_{2}\right)$ as well as the electrical double layer constant phase element $\left(Q_{2}\right)$ at the substrate/electrolyte interface. Nevertheless, as the polarization resistance of the substrate $\left(R_{2}\right)$ is one order of magnitude greater than the resistance of the coating layer $\left(R_{1}\right), R_{2}$ can be regarded to yield quantitative estimates of the corrosion rates. 
From the impedance data listed in Table 1 it is evidenced that deposition of the $\mathrm{HA}-\mathrm{ZrO}_{2}-\mathrm{Ag}$ thin film modifies the corrosion resistance of the ZrTi alloys compared to the uncoated materials as reported in ref. [18]. Resistance values are decreased by a factor of ca. 25, whereas there is a three-fold increase in the capacitance values. These are indications that the layers formed on the surface of the coated samples are less compact and must present pores, and the thin very compact inner oxide film observed in the non-coated metals cannot be formed at the buried metal/coating interface. This implies that the formation of the oxide passivating film is greatly hindered by the presence of the deposited film, and only a very thin inner oxide layer can be formed.

$R_{2}$ values increase with the elapse of time for the $\mathrm{HA}-\mathrm{ZrO}_{2}-\mathrm{Ag}$ coated alloys. In general, proteins can affect corrosion reactions in several ways, and thus shift the position of equilibrium. Thus, proteins can accelerate the dissolution of metals through their chelation effects [59-61]. But it is also possible that protein molecules adsorbed on the metal surface may hinder metal dissolution. The adsorption of organic species may cause the blocking of terminal oxygen atoms at the interface passive film/electrolyte [52]. This latter hypothesis would be confirmed by the increasing time of the capacitive arcs in the Nyquist diagrams observed in Figures 5-7 for the three coated $\mathrm{ZrTi}$ alloys under investigation. Furthermore, on the basis of EIS analysis, the corrosion resistance of ZrTi alloys immersed in Ringer's solution with added albumin protein is improved with increasing Ti content in the binary alloy.

Figure 9 displays the linear polarization curves of the coated samples in Ringer's solution with albumin protein at $37^{\circ} \mathrm{C}$. They are plotted in semi-logarithmic scale of current densities versus potential scanned from -1.0 to $+1.0 \mathrm{VsCE}$ with $1 \mathrm{mV} \mathrm{s}^{-1}$ sweep rate. The $\mathrm{HA}-\mathrm{ZrO}_{2}-\mathrm{Ag}$ coated $\mathrm{ZrTi}$ alloys present a similar anodic behaviour, where the anodic current density first described a plateau and subsequently increased steadily. Such effect has been associated to the diffusion of $\mathrm{Cl}^{-}$ions smaller than oxygen, which makes difficult for the surface to be homogeneously passivated. Table 2 gives the average values determined for both the zero corrosion potential (EzcP) and the corrosion current density ( $\left.j_{\text {corr }}\right)$ determined from the polarization curves. The linear polarization curves of $\mathrm{HA}-\mathrm{ZrO}_{2}-\mathrm{Ag}$ coated $\mathrm{Zr} 45 \mathrm{Ti}$ showed a shift of ZCP to more positive value (-0.481 $\left.\mathrm{V}_{\text {SCE}}\right)$ compared with $\mathrm{HA}-\mathrm{ZrO}_{2}$-Ag coated Zr5Ti $(-0.840 \mathrm{VsCE})$. The corrosion current density for $\mathrm{HA}-\mathrm{ZrO}_{2}-\mathrm{Ag}$ coated $\mathrm{Zr5Ti}$ is approximately five times bigger than for $\mathrm{HA}-\mathrm{ZrO}_{2}$-Ag coated $\mathrm{Zr} 45 \mathrm{Ti}$. Thus, the results indicated that $\mathrm{HA}-\mathrm{ZrO}_{2}-\mathrm{Ag}$ coated $\mathrm{Zr5Ti}$ is most easily corroded. 
Finally, Figure 10 displays the SEM images of the coated surface samples retrieved from the electrolyte after the linear potentiodynamic polarization test in Ringer's solution with albumin protein. In this way, the samples were effectively removed after the samples reached a polarization of +1.0 VSCE. No significant morphological change could be observed with the polarized samples compared to their condition prior to testing in the case of the alloys with higher Ti contents, whereas as pores and cracks on $\mathrm{HA}-\mathrm{ZrO}_{2}$-Ag coated Zr5Ti surfaces could be clearly observed.

\section{Conclusions}

The electrochemical behavior of PLD HA-ZrO2-Ag coated ZrTi in Ringer's solution with albumin protein, at $37{ }^{\circ} \mathrm{C}$ is characteristic of a metal coated by surface film with dielectric characteristics that act as a barrier for metal dissolution. The formation of a compact oxide film on the surface of the buried metal is less efficient, thus the materials with enhanced compatibility are less resistant to corrosion. Yet the coated alloys behave similarly to a passive metal in presenting a region of approximately constant passivation currents in a potential region positive to their corresponding zero current potential value in the simulated physiological solution. Better passivation characteristics are shown by the Zr45Ti alloy, and the electrochemical behaviour is greatly affected by the composition of the buried binary ZrTi alloy.

The zero corrosion potential (EzCP) of the coated Zr45Ti alloy is nobler than for the other two binary alloys, and the corrosion current density ( $j_{\text {corr }}$ ) of $\mathrm{HA}-\mathrm{ZrO}_{2}-\mathrm{Ag}$ coated $\mathrm{Zr5Ti}$ is more than five times larger than that of $\mathrm{HA}-\mathrm{ZrO}_{2}-\mathrm{Ag}$ coated $\mathrm{Zr} 45 \mathrm{Ti}$. For all coated samples, the polarization resistance $\left(R_{\mathrm{p}}\right)$ values obtained from EIS spectra, increase slowly with the time of electrode immersion indicating thicker passive layers.

Despite the decreased corrosion resistance of the $\mathrm{HA}-\mathrm{ZrO}_{2}-\mathrm{Ag}$ coated $\mathrm{ZrTi}$ alloys, it is believed that at the rate of corrosion of the Zr45Ti alloy will be adequate as not to promote adverse reactions at the bone-implant interface.

\section{Acknowledgements}

This work was supported by grants from the Romanian National Authority for Scientific Research, CNCS-UEFISCDI, project number PN-II-ID-PCE-2011-3-0218, and from the Ministerio de 
Economía y Competitividad (MINECO, Madrid, Spain) and the European Regional Development Fund (Brussels, Belgium) under Grant Number CTQ2012-36787. Thanks are due to Zirom S.A. (Giurgiu, Romania) for kindly providing the ZrTi alloys used in this work.

\section{References:}

[1] D.F. Williams, Biocompatibility of clinical implant materials, in: Biocompatibility of Clinical Impact Materials, vol. 1, D.F. Williams (Ed.); CRC Press, Boca Raton, FL, 1981, Ch. 2.

[2] P. Kovacs, J.A. Davidson, Chemical and electrochemical aspects of the biocompatibility of titanium and its alloys, in: Medical Applications of Titanium and its Alloys: the Materials and Biological Issues, S.A. Brown, J.E. Lemons (Eds.); ASTM, West Chonshohocken, PA, 1996, p. 163.

[3] M. Geetha, A.K. Singh, R. Asokamani, A.K. Gogia, Ti based biomaterials, the ultimate choice for orthopaedic implants - A review, Progress in Materials Science 54 (2009) 397-425.

[4] A. Balamurugan, S. Rajeswari, G. Balossier, A.H.S. Rebelo, J.M.F. Ferreira, Corrosion aspects of metallic implants - An overview, Materials and Corrosion 59 (2008) 855-869.

[5] J. Pan, D. Thierry, C. Leygraf, Electrochemical and XPS studies of titanium for biomaterial applications with respect to the effect of hydrogen peroxide, Journal of Biomedical Materials Research 28 (1994) 113-122.

[6] J. Pan, H. Liao, C. Leygraf, D. Thierry, J. Li, Variation of oxide film son titanium induced by osteoblastlike cell cultura, and influence o fan H2O2 pretreatment, Journal of Biomedical Materials Research 40 (1998) 244-256.

[7] G.T. Burstein, R.M. Souto, Observations of localized instability of passive titanium in chloride solution, Electrochimica Acta 40 (1995) 1881-1888.

[8] R.M. Souto, G.T. Burstein, A preliminary investigation into the microscopic depassivation of passive titanium implant materials in vitro, Journal of Materials Science: Materials in Medicine 7 (1996) 337343.

[9] G.T. Burstein, C. Liu, R.M. Souto, The effect of temperature on the nucleation of corrosion pits on titanium in Ringer's physiological solution, Biomaterials 26 (2005) 245-256.

[10] C.P. Case, V.G. Langkamer, C. Jamec, M.R. Palmer, A.J. Kemp, P.F. Heap, L. Solomon, Widespread dissemination of metal debris from implants, Journal of Bone \& Joint Surgery 76B (1994) 701-712. 
[11] I. Milošev, V. Antolič, A. Minovič, A. Cör, S. Herman, V. Pavlovčič, P. Campbell, Extensive metallosis and necrosis in failed prostheses with cemented titanium-alloy stems and ceramic heads, Journal of Bone \& Joint Surgery 82B (2000) 352-357.

[12] P. Korovessis, G. Petsinis, M. Repanti, T. Repantis, Metallosis after contemporary metal on metal total hip arthroplasty. Five to nine year follow up, Journal of Bone \& Joint Surgery American 88 (2006) 1183-1191.

[13] O. Addison, A.J. Davenport, R.J. Newport, S. Kalra, M. Monir, J.F.W. Mosselmans, D. Props, R.A. Martin, Do 'passive’ medical titanium surfaces deteriorate in service in the absence of wear?, Journal of the Royal Society Interface 9 (2012) 3161-3164.

[14] N.J. Hallab, S. Anderson, M. Caicedo, A. Brasher, K. Mikecz, J.J. Jacobs, Effects of soluble metals on human peri-implant cells, Journal of Biomedical Materials Research 74A (2005) 124-140.

[15] S. Rao, Y. Okazaki, T. Tateishi, T. Ushida, Y. Ito, Cytocompatibility of new Ti alloy without Al and $\mathrm{V}$ by evaluating the relative growth ratios of fibroblasts L929 and osteoblasts MC3T3-E1 cells, Materials Science and Engineering C 4 (1997) 311-314.

[16] E. Kobayashi, S. Matsumoto, H. Doi, T. Yoneyama, H. Hamanaka, Mechanical properties of the binary titanium-zirconium alloys and their potential for biomedical materials, Journal of Biomedical Materials Research 29 (1995) 943-950.

[17] F.E.F. Almeida, R.A.C. Santana, S.J.G. Lima, S. Prasad, R.M. Gomes, Microstructure and electrochemical behavior of in vitro Ti-26Nb, Ti-26Zr and Ti-26Ta alloys processed by levitation melting technique, American Journal of Materials Science 2 (2012) 77-81.

[18] G. Bolat, J. Izquierdo, J.J. Santana, D. Mareci, R.M. Souto, Electrochemical characterization of ZrTi alloys for biomedical applications, Electrochimica Acta 88 (2013) 447-456.

[19] D. Mareci, G. Bolat, A. Cailean, J.J. Santana, J. Izquierdo, R.M. Souto, Effect of acidic fluoride solution on the corrosion resistance of ZrTi alloys for dental implant application, Corrosion Science 87 (2014) 334-343.

[20] J. Izquierdo, G. Bolat, D. Mareci, C. Munteanu, S. González, R.M. Souto, Electrochemical behaviour of ZrTi alloys in artificial physiological solution simulating in vitro inflammatory conditions, Applied Surface Science 313 (2014) 259-266.

[21] G. Bolat, J. Izquierdo, D. Mareci, D. Sutiman, R.M. Souto, Electrochemical characterization of ZrTi alloys for biomedical applications. Part 2. The effect of thermal oxidation, Electrochimica Acta 106 (2013) 432-439. 
[22] R. Bosco, J. van den Beucken, S. Leeuwenburgh, J. Jansen, Surface engineering for bone implants: A trend from passive to active surfaces, Coatings 2 (2012) 95-119.

[23] P. Ducheyne, S. Radin, M. Heughebaert, J.C. Heughebaert, Calcium phosphate ceramic coatings on porous titanium: effect of structure and composition on electrophoretic deposition, vacuum sintering and in vitro dissolution, Biomaterials 11 (1990) 244-254.

[24] I.C. Lavos-Valereto, B. Ko, C. Rossa, E. Marcantonio, A.C. Zavaglia, A study of histological responses from Ti-6Al-7Nb alloy dental implants with and without plasma-sprayed hydroxyapatite coating in dogs, Journal of Materials Science: Materials in Medicine 12 (2001) 273-276.

[25] C.Y. Yang, R.M. Lin, B.C. Wang, T.M. Lee, E. Chang, Y.S. Hang, P.Q. Chen, In vitro and in vivo mechanical evaluations of plasma-sprayed hydroxyapatite coatings on titanium implants: The effect of coating characteristics, Journal of Biomedical Materials Research 37 (1997) 335-345.

[26] F.J. Garcia-Sanz, M.B. Mayor, J.L. Arias, J. Pou, B. Leon, M. Perez-Amor, Hydroxyapatite coatings: a comparative study between plasma-spray and pulsed laser deposition techniques, Journal of Materials Science: Materials in Medicine 8 (1997) 861-865.

[27] X. Meng, T.Y. Kwon, K.H. Kim, Hydroxyapatite coating by electrophoretic deposition at dynamic voltage, Dental Materials Journal 27 (2008) 666-671.

[28] O. Albayrak, O. El-Atwani, S. Altintas, Hydroxyapatite coating on titanium substrate by electrophoretic deposition method: effects of titanium dioxide inner layer on adhesion strength and hydroxyapatite decomposition, Surface and Coatings Technology 202 (2008) 2482-2487.

[29] D.M. Liu, Q. Yang, T . Troczynski, W.J. Tseng, Structural evolution of sol-gel-derived hydroxyapatite, Biomaterials 23 (2002) 1679-1687.

[30] V. Nelea, C. Morosanu, M. Iliescu, I.N. Mihailescu, Hydroxyapatite thin films grown by pulsed laser deposition and radio-frequency magnetron sputtering: comparative study, Applied Surface Science 228 (2004) 346-356.

[31] G. Wang, F. Meng, C. Ding, P.K. Chu, X. Liu, Microstructure, bioactivity and osteoblast behavior of monoclinic zirconia coating with nanostructured surface, Acta Biomaterialia 6 (2010) 9901000.

[32] G. Wang, X. Liu, C. Ding, Phase composition and in-vitro bioactivity of plasma sprayed calcia stabilized zirconia coatings, Surface and Coatings Technology 202 (2008) 5824-5831. 
[33] Y. Yan, Y. Han, C. Lu, The effect of chemical treatment on apatite-forming ability of the macroporous zirconia films formed by micro-arc oxidation, Applied Surface Science 254 (2008) 4833-4839.

[34] Y. Han, Y. Yan, C. Lu, Ultraviolet-enhanced bioactivity of $\mathrm{ZrO}_{2}$ films prepared by micro-arc oxidation, Thin Solid Films 517 (2009) 1577-1581.

[35] Y. Yan, Y. Han, Structure and bioactivity of micro-arc oxidized zirconia films, Surface and Coatings Technology 201 (2007) 5692-5695.

[36] Y. Chen, X. Zheng, Y. Xie, C. Ding, H. Ruan, C. Fan, Anti-bacterial and cytotoxicity of plasma sprayed silver-containing HA coatings, Journal of Materials Science: Materials in Medicine 19 (2008) 3603-3609.

[37] M. Ziberman, J.J. Elsner, Antibiotic-eluting medical devices for various applications, Journal of Controlled Release 130 (2008) 202-215.

[38] W.J. Schreurs, H. Rosenberg, Effect of silver ions on transport and retention of phosphate by Escherichia coli, Journal of Bacteriology 152 (1982) 7-13.

[39] D. Lee, R.E. Cohen, M.F. Rubner, Antibacterial properties of Ag nanoparticle loaded multilayers and formation of magnetically directed antibacterial microparticles, Langmuir 21 (2005) 96519659.

[40] K.B. Holt, A.J. Bard, Interaction of silver(I) ions with the respiratory chain of escherichia coli: An electrochemical and scanning electrochemical microscopy study of the antimicrobial mechanism of micromolar $\mathrm{Ag}^{+}$, Biochemistry 44 (2005) 13214-13223.

[41] C.-N. Lok, C.-M. Ho, R. Chen, Q.-Y. He, W.-Y. Yu, H. Sun, P.K.-H Tam, J.-F. Chiu, C.-M. Che, Silver nanoparticles: partial oxidation and antibacterial activities, JBIC Journal of Biological Inorganic Chemistry 12 (2007) 527-534.

[42] B.B. Zhang, K.J. Qiu, B.L. Wang, L. Li, Y.F. Zheng, Surface characterization and cell response of binary Ti-Ag alloys with CP Ti as material control, Journal of Materials Science \& Technology 28 (2012) 779-784.

[43] D. Ionita, M. Grecu, C. Ungureanu, I. Demetrescu, Antimicrobial activity of the surface coatings on TiAlZr implant biomaterial, Journal of Bioscience and Bioengineering 112 (2011) 630-634.

[44] D. Ionita, M. Dilea, I. Titorencu, I. Demetrescu, Merit and demerit effects of silver nanoparticles in the bioperformance of an electrodeposited hydroxyapatite:nanosilver composite coating, Journal of Nanoparticle Research 14 (2012) 1152-1-10. 
[45] D. Brodoceanu, N.D. Scarisoreanu, M. Filipescu, G.N. Epurescu, D.G. Matei, P. Verardi, F. Craiun, M. Dinescu, Pulsed laser deposition of oxide thin films, in: Plasma Production by Laser Ablation PPLA 2003, S. Gammino, A.M. Mezzasalma, F. Neri, L. Torresi (Eds.), World Scientific, Singapore, 2004, pp. 41-46.

[46] D.G. Wang, C.Z. Chen, Q.S. Ma, Q.P. Jin, H.C. Li, A study on in vitro and in vivo bioactivity of HA/45S5 composite films by pulsed laser deposition, Applied Surface Science 270 (2013) 667674.

[47] S.R. Sousa, M.A. Barbosa, Corrosion resistance of titanium CP in saline physiological solutions with calcium phosphate and proteins, Clinical Materials 14 (1993) 287-294.

[48] M.A. Khan, R.L. Williams, D.F. Williams, The corrosion behaviour of Ti-6Al-4V, Ti-6Al-7Nb and Ti-13Nb-13Zr in protein solutions, Biomaterials 20 (1999) 631-637.

[49] M.A. Khan, R.L. Williams, D.F. Williams, Conjoint corrosion and wear in titanium alloys, Biomaterials 20 (1999) 765-772.

[50] J. Lima, S.R. Sousa, A. Ferreira, M.A. Barbosa, Interactions between calcium, phosphate, and albumin on the surface of titanium, Journal of Biomedical Materials Research 55 (2001) 45-53.

[51] F. Contu, B. Elsener, H. Böhni, Characterization of implant materials in fetal bovine serum and sodium sulfate by electrochemical impedance spectroscopy. I. Mechanically polished samples, Journal of Biomedical Materials Research 62 (2002) 412-421.

[52] F. Contu, B. Elsener, H. Böhni, Characterization of implant materials in fetal bovine serum and sodium sulfate by electrochemical impedance spectroscopy. II. Coarsely sandblasted samples, Journal of Biomedical Materials Research A 67 (2003) 246-254.

[53] X. Cheng, S.G. Roscoe, Corrosion behavior of titanium in the presence of calcium phosphate and serum proteins, Biomaterials 26 (2005) 7350-7356.

[54] N. Padilla, A. Bronson, Electrochemical characterization of albumin protein on Ti-6AL-4V alloy immersed in a simulated plasma solution, Journal of Biomedical Materials Research A 81 (2007) 531-543.

[55] M. Darroudi, A.K. Zak, M.R. Muhamad, N.M. Huang, M. Hakimi, Green synthesis of colloidal silver nanoparticles by sonochemical method, Materials Letters 66 (2012) 117-120.

[56] Y. Kojima, K. Kitazawa, N. Nishimiya, Synthesis of nano-sized hydroxyapatite by ultrasound irradiation, Journal of Physics: Conference Series 339 (2012) 012001. 
[57] R. Chelariu, D. Mareci, G. Bolat, C.A. Peptu, D. Cailean, Electrochemical characterization of surface modification for Ti6Al7Nb implants with hydroxyapatite-zirconia nanoparticles synthesis by ultrasound irradiations, Materials and Corrosion 66 (2015) 573-578.

[58] D. Mareci, I. Rusu, R. Chelariu, G. Bolat, C. Munteanu, D. Sutiman, R.M. Souto, Application of dynamic electrochemical impedance spectroscopy to the evaluation of the corrosion resistance of a historic bronze object in artificial acid rainwater, European Journal of Science and Theology 9 (2013) 189-199.

[59] S.L. Assis, I. Costa, Electrochemical evaluation of Ti-13Nb-13Zr, Ti-6Al-4V and Ti-6Al-7Nb alloys for biomedical applications by long-term applications tests, Materials and Corrosion 58 (2007) 329-333.

[60] E. Kobayashi, T.J. Wang, H. Doi, T. Yoneyama, H. Hamanaka, Mechanical properties and corrosion resistance of Ti-6Al-7Nb alloy dental castings, Journal of Materials Science: Materials in Medicine 9 (1998) 567-574.

[61] S. Omanovic, S.G. Roscoe, Electrochemical studies of the adsorption behavior of bovine serum albumin on stainless steel, Langmuir 15 (1999) 8315-8321. 


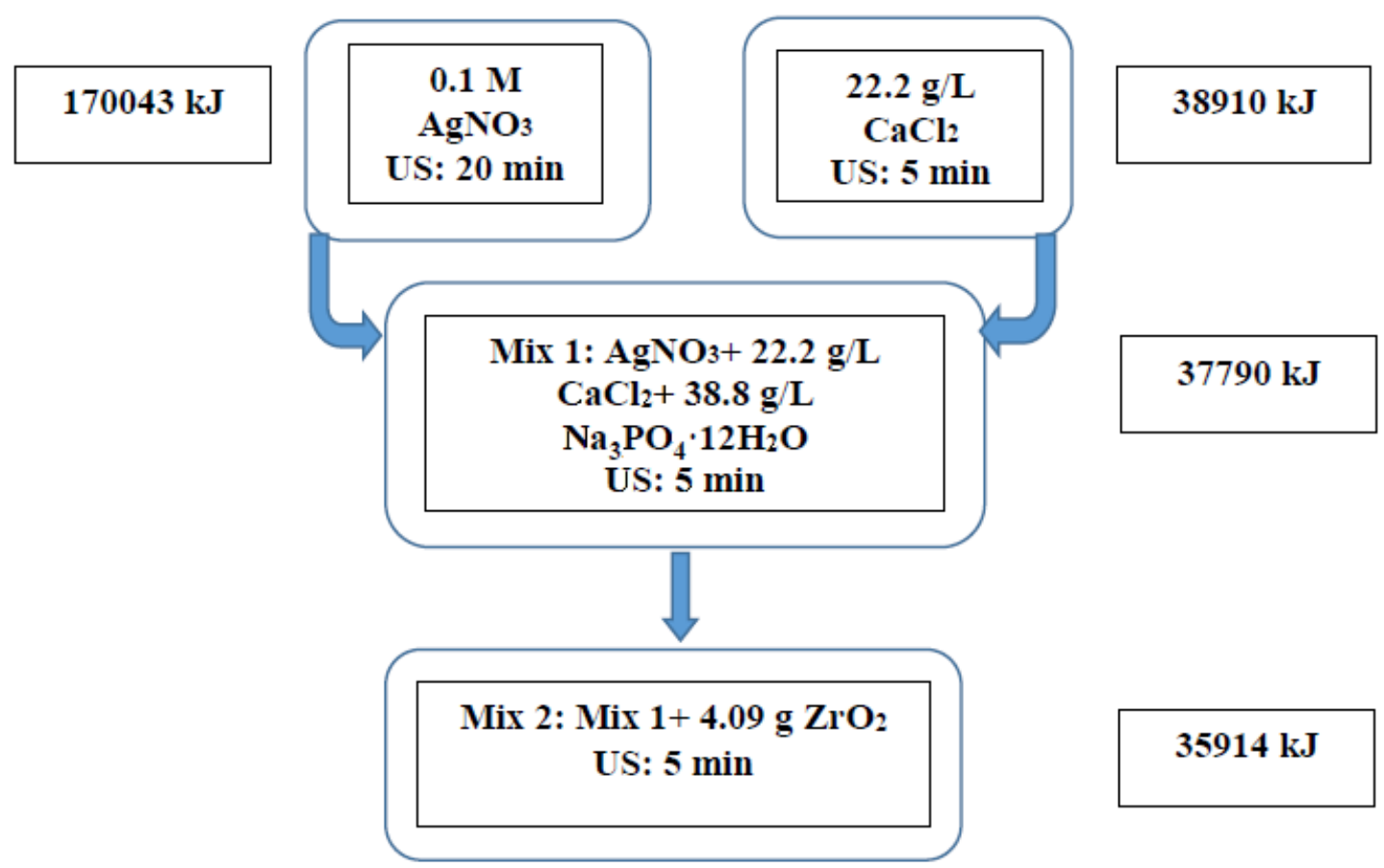

Figure 1

Schematic representation of the preparation stage and the US parameters employed for the fabrication of $\mathrm{HA}-\mathrm{ZrO}_{2}$-Ag coatings: time and delivered energy.

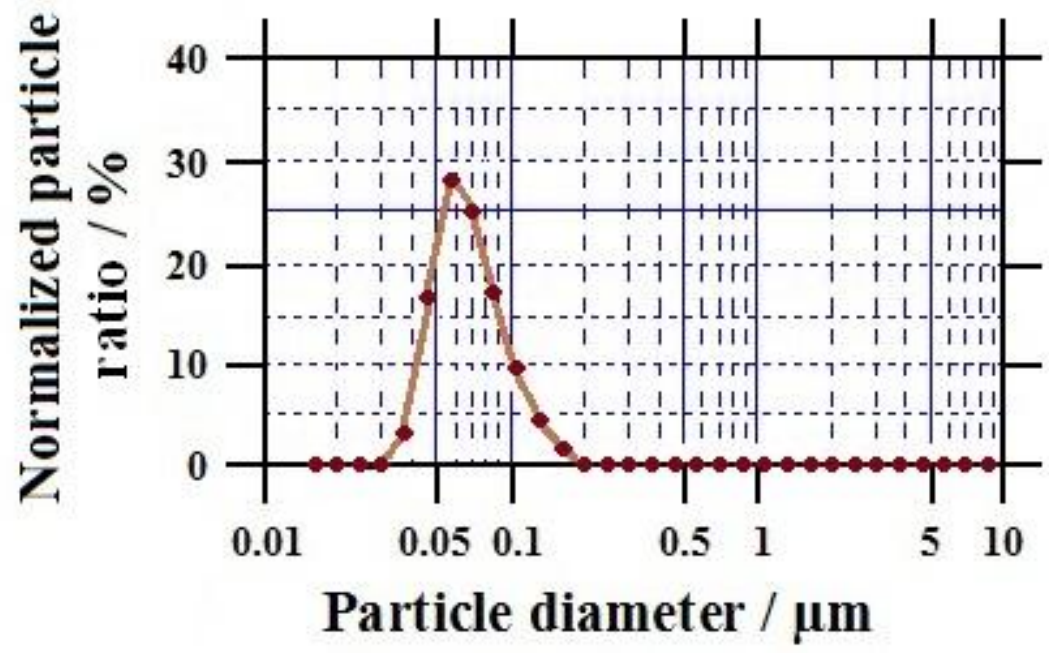

Figure 2

Dimensional distribution of $\mathrm{HA}-\mathrm{ZrO}_{2}$-Ag particles. 

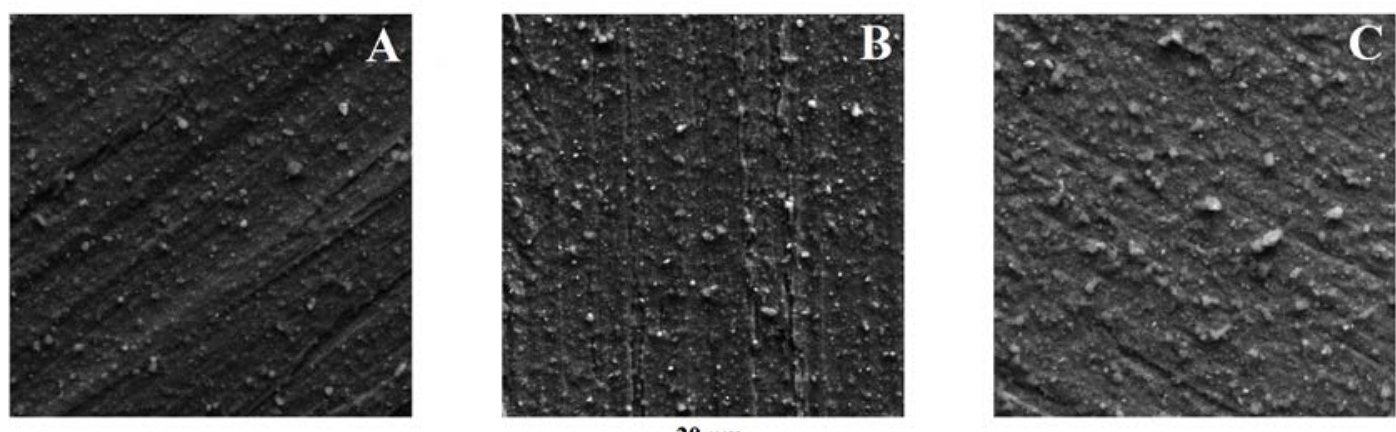

$20 \mu \mathrm{m}$

Figure 3

SEM micrographs of HA-ZrO2-Ag coated ZrTi samples: (A) Zr5Ti, (B) Zr25Ti, and (C) Zr45Ti.

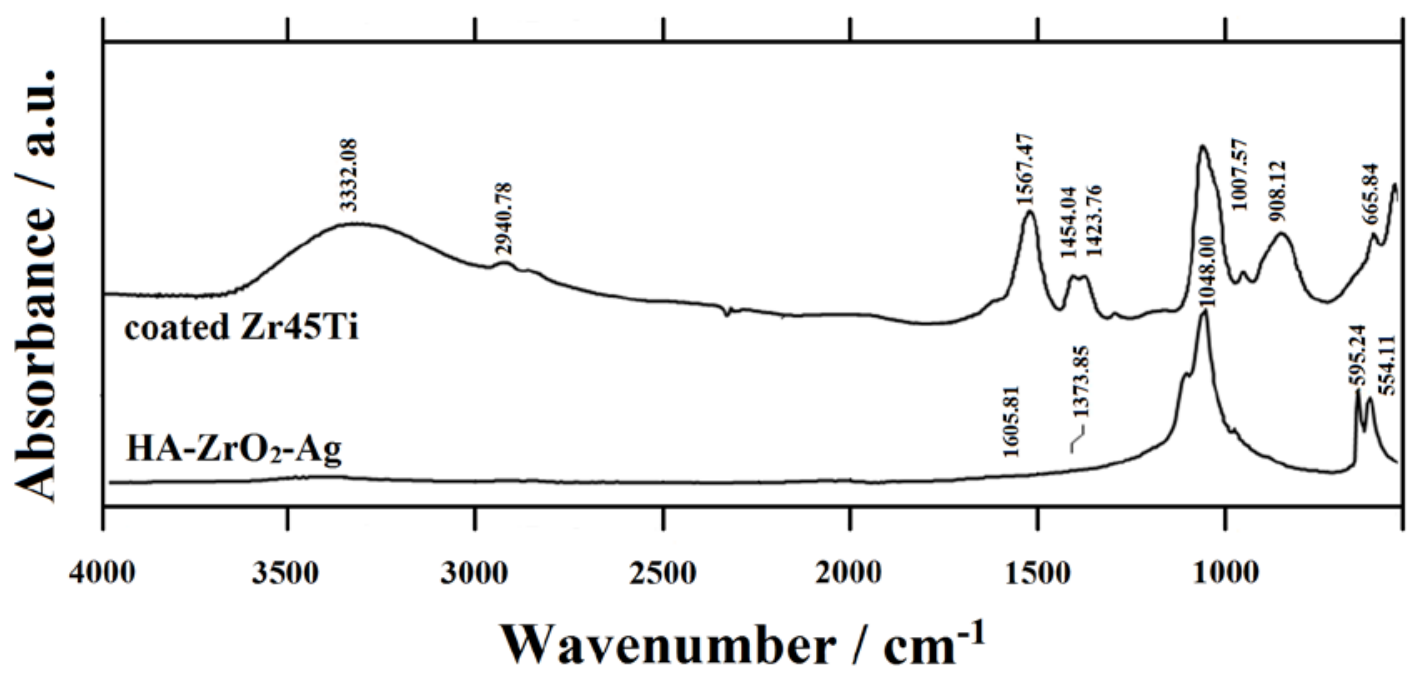

\section{Figure 4}

Representative micro-FTIR spectra for HA-ZrO2-Ag coated Zr45Ti alloy. For the sake of comparison, the $\mathrm{HA}-\mathrm{ZrO}_{2}-\mathrm{Ag}$ spectrum according to OPUS software library has been included in the graph. 

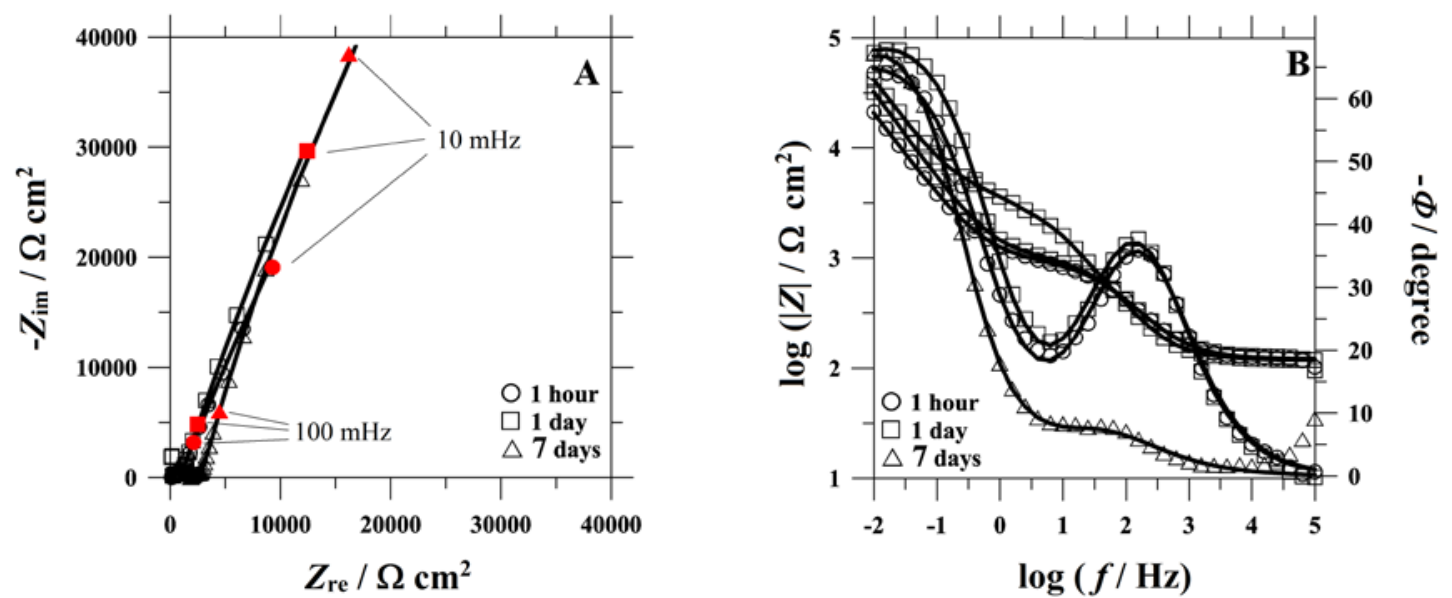

Figure 5

EIS spectra obtained during immersion in Ringer's solution with albumin protein on Zr5Ti alloy coated with the $\mathrm{HA}-\mathrm{ZrO}_{2}-\mathrm{Ag}$ coating. (A) Nyquist, and (B) Bode diagrams.
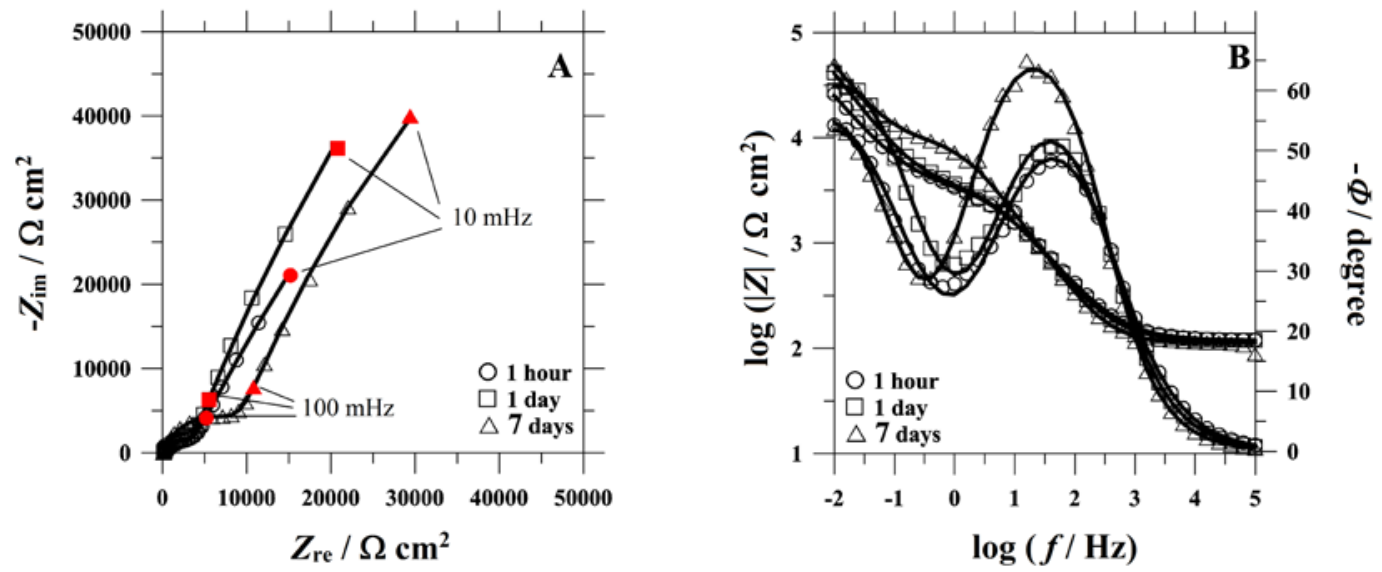

\section{Figure 6}

EIS spectra obtained during immersion in Ringer's solution with albumin protein on Zr25Ti alloy coated with the $\mathrm{HA}-\mathrm{ZrO}_{2}-\mathrm{Ag}$ coating. (A) Nyquist, and (B) Bode diagrams. 

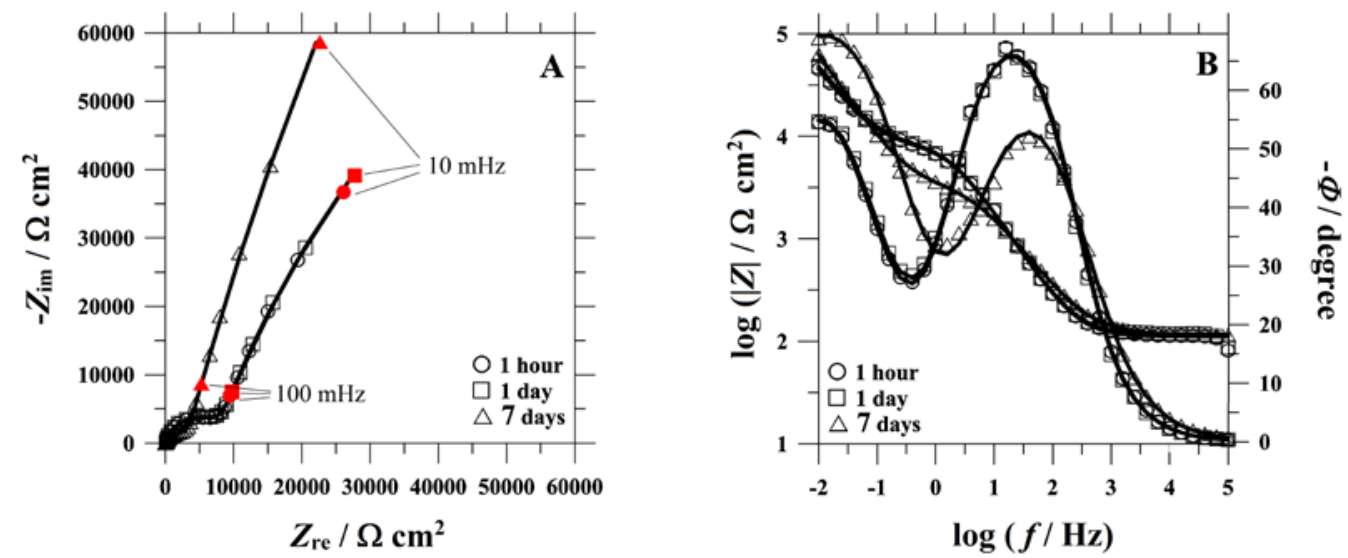

\section{Figure 7}

EIS spectra obtained during immersion in Ringer's solution with albumin protein on Zr45Ti alloy coated with the $\mathrm{HA}-\mathrm{ZrO}_{2}-\mathrm{Ag}$ coating. (A) Nyquist, and (B) Bode diagrams.

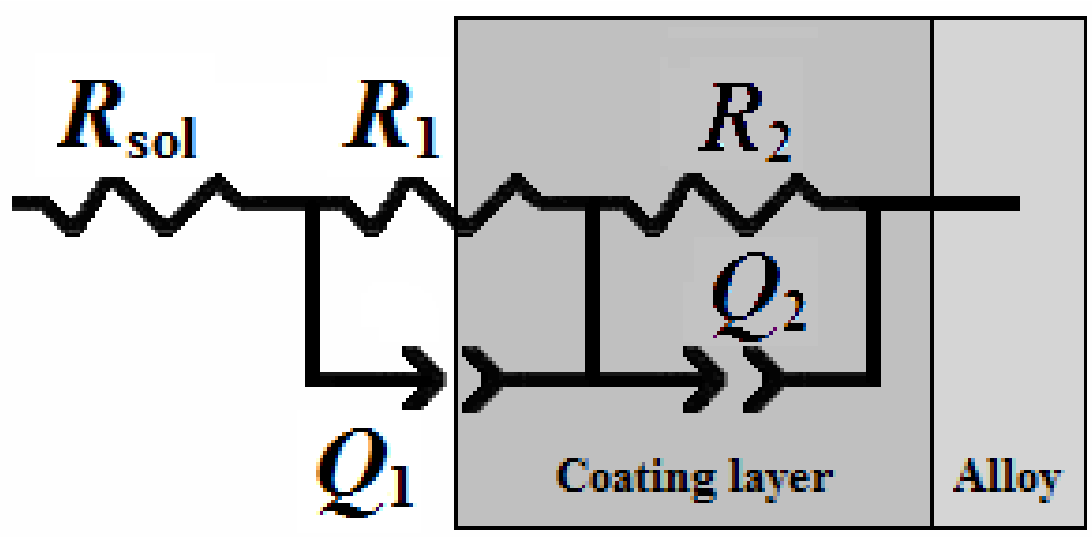

Figure 8

Equivalent circuit (EC) used for analysis of EIS spectra. 


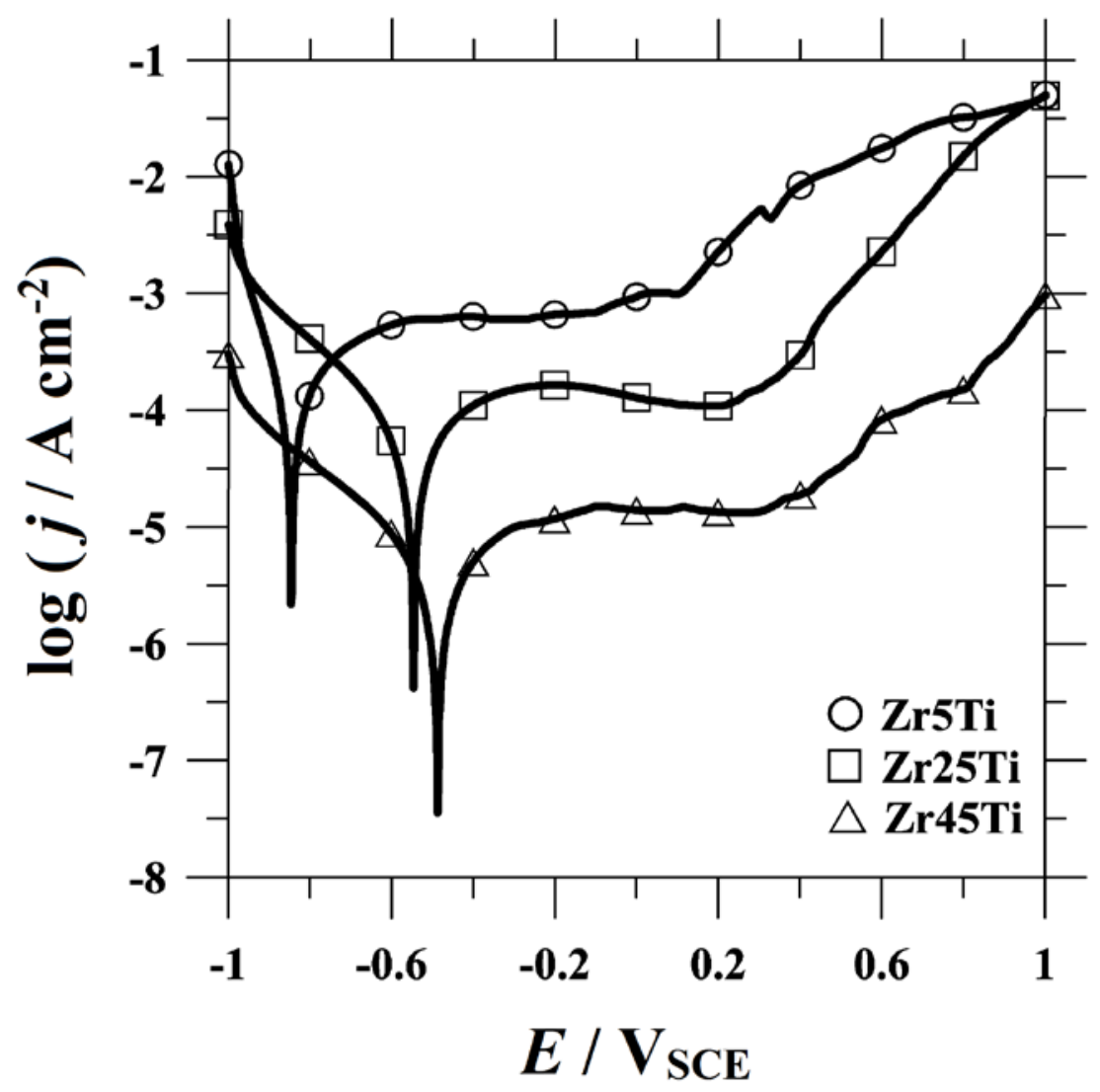

\section{Figure 9}

Representative potentiodynamic polarization curves obtained for $\mathrm{HA}-\mathrm{ZrO} 2-\mathrm{Ag}$ coated $\mathrm{ZrTi}$ alloys after 7 days immersion in Ringer's solution with albumin protein at $37^{\circ} \mathrm{C}$.
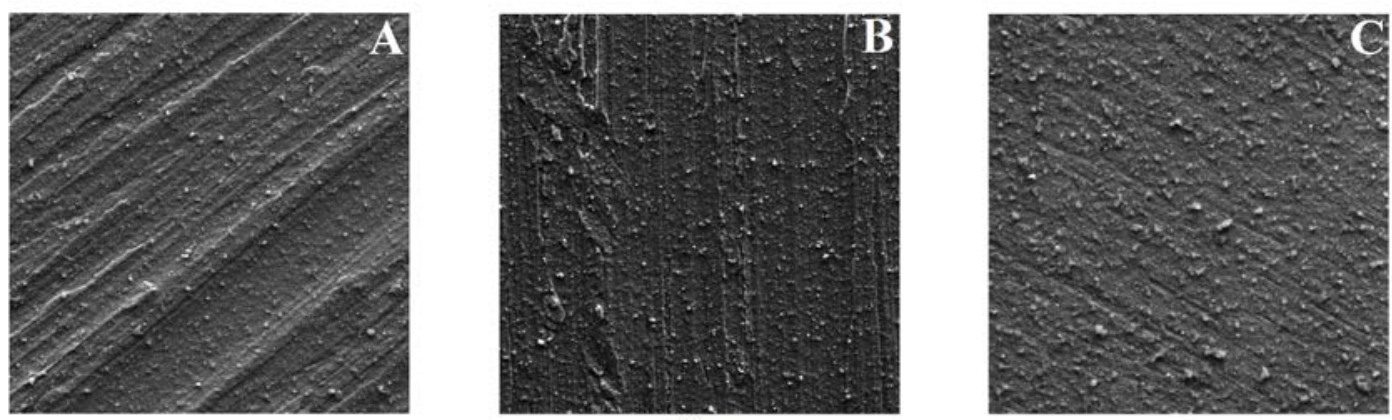

$50 \mu \mathrm{m}$

Figure 10 
SEM micrographs of $\mathrm{HA}-\mathrm{ZrO}_{2}-\mathrm{Ag}$ coated $\mathrm{ZrTi}$ samples retrieved at $+1.0 \mathrm{VSCE}$ alloys after recording the potentiodynamic polarization curves given in Figure 9. Alloy substrate: (A) Zr5Ti, (B) Zr25Ti, and (C) Zr45Ti.

\section{Tables captions}

\section{Table 1}

Impedance parameters of $\mathrm{HA}-\mathrm{ZrO}_{2}-\mathrm{Ag}$ coated $\mathrm{ZrTi}$ alloys immersed in naturally-aerated Ringer's solution containing albumin protein at $37^{\circ} \mathrm{C}$ after different immersion periods.

\section{Table 2}

Corrosion parameters (and standard deviation values) determined from the potentiodynamic polarization curves for $\mathrm{HA}-\mathrm{ZrO}_{2}$ - $\mathrm{Ag}$ coated $\mathrm{ZrTi}$ alloys in naturally-aerated Ringer's solution containing albumin protein at $37^{\circ} \mathrm{C}$. 